\title{
Single- and Double-Switch Cell Voltage Equalizers for Series-Connected Lithium-Ion Cells and Supercapacitors
}

\author{
Masatoshi Uno
}

Additional information is available at the end of the chapter

http://dx.doi.org/10.5772/52215

\section{Introduction}

As demands for energy-efficient electrical devices and equipment continue to increase, the role of energy storage devices and systems becomes more and more important. Applications of such energy storage devices range from portable electronic devices, where a single cell is sufficient to provide adequate run time, to electric vehicles that require more than 100 cells in series to produce a sufficient high voltage to drive motors. Lithium-ion batteries (LIBs) are the most prevalent and promising because of their highest specific energy among commercially available secondary battery technologies.

Supercapacitor (SC) technologies, including traditional electric double-layer capacitors and lithium-ion capacitors (hybrid capacitors that combine features of double-layer capacitors and LIBs) are also drawing significant attention, because of their outstanding service life over a wide temperature range, high-power capability, and high-energy efficiency performance. The use of such SC technologies has traditionally been limited to high-power applications such as hybrid electric vehicles and regenerative systems in industries, where high-power energy buffers are needed to meet short-term large power demands. But it is found that SC technologies also have a great potential to be alternative energy storage sources to traditional secondary batteries once their superior life performance over a wide temperature range is factored in (Uno, 2011; Uno \& Tanaka, 2011).

The voltage of single cells is inherently low, typically lower than $4.2,2.7$, and $3.8 \mathrm{~V}$ for lithium-ion cells, traditional electric double-layer capacitors, and lithium-ion capacitors, respectively. Hence in most practical uses, a number of single cells need to be connected in series to produce a high voltage level to meet the load voltage requirement. Voltages of 
series-connected cells are gradually imbalanced because their individual properties, such as capacity/capacitance, self-discharge rate, and internal impedance, are different from each other. Nonuniform temperature gradient among cells in a battery pack/module also lead to nonuniform self-discharging that accelerates voltage imbalance. In a voltage-imbalanced battery/module, some cells in the series connection may be overcharged and overdischarged during the charging and discharging processes, respectively, even though the average voltage of the series-connected cells is within the safety boundary. Using LIBs/SCs beyond the safety boundary not only curtails their operational life but also undermines their electrical characteristics. Overcharging must be prevented especially for LIBs since it may result in fire or even an explosion in the worst situation.

In addition to the safety issues mentioned above, the voltage imbalance also reduces the available energies of cells. When charging the cells in series, charging processes must be halted as soon as the most charged cell reaches the upper voltage limit, above which accelerated irreversible deterioration is very likely. Similarly, in order to avoid overdischarging during discharging processes, the least charged cell in the series connection limits the discharging time as a whole. Thus, voltage imbalance should be minimized in order to prolong life time as well as to maximize the available energies.

Various kind of equalization techniques have been proposed, demonstrated, and implemented for LIBs and SCs (Cao et al., 2008; Guo et al., 2006). However, conventional equalization techniques have one of the following major drawbacks:

1. Low energy efficiency because of the dissipative equalization mechanism.

2. Complex circuitry and control because of high switch count.

3. Design difficulty and poor modularity because of the need for a multi-winding transformer that imposes strict parameter matching among multiple secondary windings.

This chapter presents single- and double-switch cell voltage equalizers for series-connected lithium-ion cells and SCs. The equalization process of the equalizers is nondissipative, and a multi-winding transformer is not necessary. Hence, all the issues underlying the conventional equalizers listed above can be addressed by the presented equalizers. In Section 2, the above-mentioned issues are discussed in detail, and conventional cell voltage equalizers are briefly reviewed. In Section 3, single-switch cell voltage equalizers based on multi-stacked buck-boost converters are presented. In the single-switch equalizers, although multiple inductors are required, the circuitry can be very simple because of the single-switch configuration. Section 4 introduces double-switch cell voltage equalizers using a resonant inverter and a voltage multiplier. Although the circuitry is slightly more complex than the single-switch equalizers, its single-magnetic configuration minimizes circuit size and cost. Detailed operation analyses are mathematically made, and experimental equalization tests performed for series-connected SCs and lithium-ion cells using the prototype of the singleand double-switch equalizers are shown. Finally, in Section 5, the presented single- and double-switch equalizers are compared with conventional equalizers in terms of the required number of circuit components. 


\section{Conventional equalization techniques}

\subsection{Dissipative equalizers}

The most common and traditional approach involves the use of dissipative equalizers, which do not require high-frequency switching operations. With dissipative equalizers, the voltage of series-connected cells can be equalized by removing stored energy or by shunting charge current from the cells with higher voltage. During the equalization process, the excess energy or current is inevitably dissipated in the form of heat, negatively influencing the thermal system of batteries/modules. Dissipative equalizers introduce advantages over nondissipative equalizers in terms of circuit simplicity and cost. The dissipative equalizers can be categorized into two groups: passive and active equalizers.

Fig. 1(a) shows the simplest solution using passive resistors. Voltage imbalance gradually decreases because of different self-discharge through resistors depending on cell voltages. Although simple, the relentless power loss in resistors reduces the energy efficiency, depending on the resistance values, and hence, this equalizer is rarely used in practice.

Another concept of a passive dissipative equalizer is the use of Zener diodes, as shown in Fig. 1(b). Cell voltages exceeding a Zener voltage level are cramped by Zener diodes. The power loss in the Zener diodes during the rest period is negligibly low depending on their leakage current. However, these diodes must be chosen to be capable of the largest possible charge current because the charge current flows through them when the cell voltage reaches or exceeds the Zener voltage level. In addition, a great temperature dependency of the Zener voltage, which may not be acceptable in most applications, should be factored in.

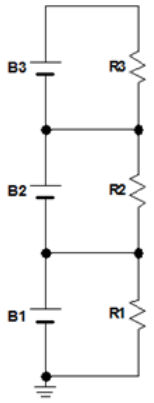

(a)

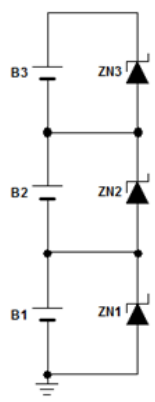

(b)

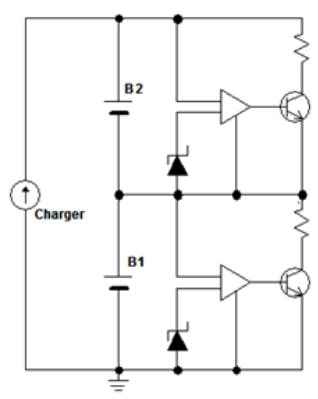

(c)

Figure 1. Passive dissipative equalizers using (a) resistors and (b) Zener diodes, and (c) active shunting equalizer.

Fig. 1(c) shows a schematic drawing of shunting equalizers (Isaacson et al., 2000; Uno, 2009). Cell voltages are monitored and compared with a preset voltage level (shunt voltage level). When the cell voltage reaches or exceeds the shunt voltage level, the charge current is bypassed through a transistor to reduce the net charge current. The product of cell voltage and shunt current is the power dissipation in the equalizer. The shunting equalizer needs as 
many switches, voltage sensors, and comparators as the number of series connection of cells. In addition, this equalizer inevitably causes energy loss in the form of heat generation during the equalization process. The operation flexibility is also poor because cells are equalized only during the charging process, especially at fully charged states.

Although dissipative equalization techniques seem less effective compared with nondissipative equalizers, which are reviewed in the following subsection, the shunting equalizers are widely used in various applications, and a number of battery management ICs that include shunting equalizers are available because of their simplicity, good modularity (or extendibility), and cost effectiveness.

\subsection{Nondissipative equalizers}

Nondissipative equalizers that transfer charges or energies among series-connected cells are considered more suitable and promising than dissipative equalizers in terms of energy efficiency and thermal management. In addition, nondissipative equalizers (including single- and double-switch equalizers presented in this chapter) are usually operational during both charging and discharging, and hence, operation flexibility can be improved compared with dissipative equalizers. Numerous nondissipative equalization techniques have been proposed and demonstrated. Representative nondissipative equalizer topologies are reviewed in the following subsections.

\subsubsection{Individual cell equalizer}

Fig. 2(a) depicts a schematic drawing of the individual cell equalizer (ICE) (Lee \& Cheng, 2005). ICEs are typically based on individual bidirectional dc-dc converters such as switched capacitor converters (Pascual \& Krein, 1997; Uno \& Tanaka, 2011) and buck-boost converters (Nishijima et al., 2000), as shown in Figs. 2(b) and (c), respectively. Other types of bidirectional converters, such as resonant switched capacitor converters and Ćuk converters (Lee \& Cheng, 2005), can also be used for improving equalization efficiencies. In ICE topologies, the charges or energies of the series-connected cells can be transferred between adjacent cells to eliminate cell voltage imbalance. The number of series connection of cells can be arbitrary extended by adding the number of ICEs.

Since these ICE topologies are derived from multiple individual bidirectional dc-dc converters, numerous switches, sensors, and switch drivers are required in proportion to the number of series-connected energy storage cells. Therefore, their circuit complexity and cost are prone to increase, especially for applications needing a large number of series connections, and their reliability decreases as the number of series connections increases.

\subsubsection{Equalizers using a multi-winding transformer}

In cell voltage equalizers using a multi-winding transformer based on flyback and forward converters, as shown in Figs. 3(a) and (b), respectively, the energies of series- 
connected cells can be redistributed via a multi-winding transformer to the cell(s) having the lowest voltage (Kutkut, et al., 1995). The required number of switches in the multiwinding transformer-based equalizers is significantly less than those required in ICE topologies. However, these topologies need a multi-winding transformer that must be customized depending on the number of series connections, and hence, the modularity is not good. In addition, since parameter mismatching among multiple secondary windings results in voltage imbalance that can never be compensated by control, multi-winding transformers must be designed and made with great care (Cao et al., 2008; Guo et al., 2006). In general, the difficulty of parameter matching significantly increases with the number of windings. Therefore, their applications are limited to modules/batteries with a few series connections.

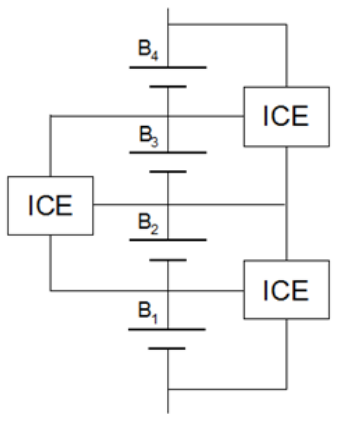

(a)

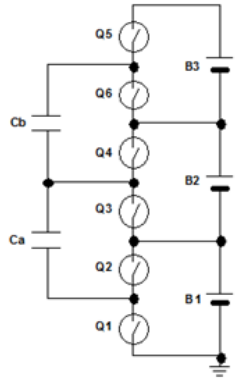

(b)

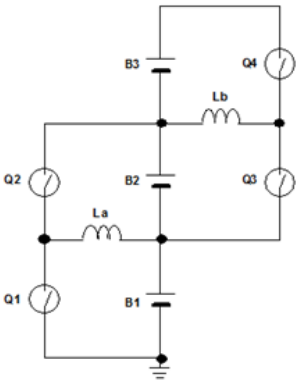

(c)

Figure 2. (a) Generic configuration of individual cell equalizer, (b) switched capacitor-based equalizer, and (c) buck-boost converter-based equalizer.

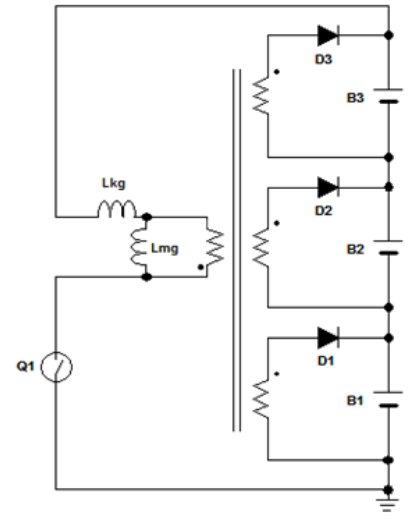

(a)

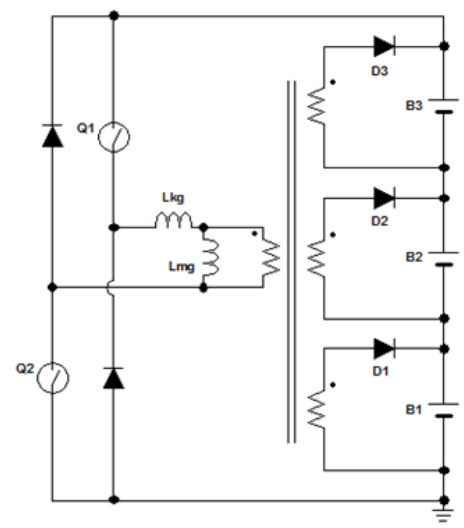

(b)

Figure 3. Equalizers using a multi-winding transformer: (a) flyback converter-based and (b) forward converter-based equalizers. 


\subsubsection{Equalizers using a single converter with selection switches}

Figs. 4(a) and (b) show equalizers using a single converter and selection switches based on the flying capacitor and the flyback converter, respectively (Kim et al., 2011). In these topologies, individual cell voltages are monitored, and the cell(s) with the lowest and/or highest voltages are determined. In the flying capacitor-based equalizer, shown in Fig. 4(a), the energy of the most charged cell is delivered to the least charged cell via the flying capacitor $C$ by selecting proper switches. In the flyback converter-based equalizer, shown in Fig. 4(b), the energy of series-connected cells is redistributed to the least charged cell via the flyback converter and properly selected switches.

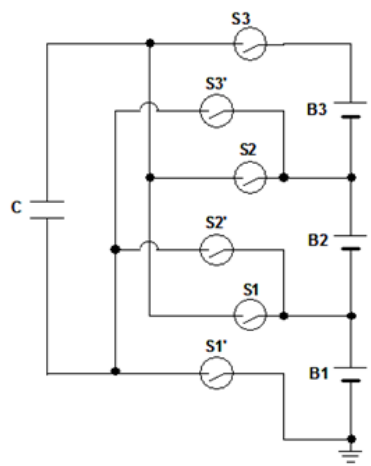

(a)

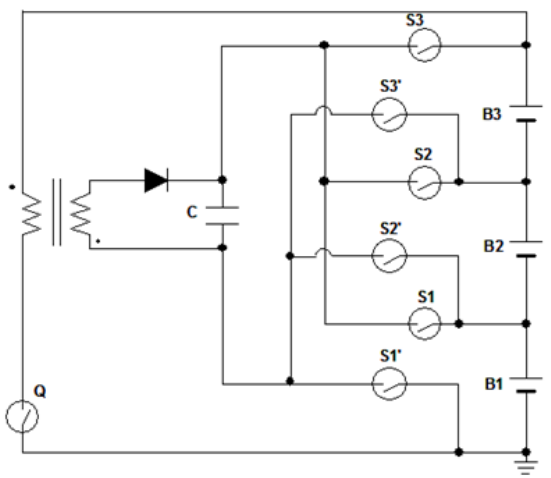

(b)

Figure 4. Equalizers using a single converter with selection switches based on (a) flying capacitor and (b) flyback converter.

These topologies can reduce the number of passive components significantly when compared with ICE topologies shown in Fig. 2, and do not need a multi-winding transformer. However, the required number of switches is still large (proportional to the number of series connections), and furthermore, microcontroller- or DSP-based intelligent management is mandatory because target cell(s) (i.e., the least and/or most charged cells) must be determined for equalization to be implemented.

\section{Single-switch cell voltage equalizer using multi-stacked buck-boost converters}

\subsection{Circuit description and major benefits}

The single-switch cell voltage equalizers are derived by multi-stacking traditional buckboost converters that consist of two inductors and one coupling capacitor (Uno \& Tanaka, 2011). Candidate topologies, which can be used as a basic topology, are shown in Fig. 5. The single-ended primary inductor converter (SEPIC) and Zeta converters can be simply adapted as the basic topology. On the other hand, the Ćuk topology cannot be used 
without a transformer because of its inverting property. Out of the three candidates shown in Fig. 5, the Ćuk converter is the best in terms of current pulsation at its input and output because inductors $\mathrm{Lin}_{\text {in }}$ and Lout are connected in series to the input and output, respectively. Although the SEPIC and Zeta converter can be adapted without a transformer, transformer-less operation may suffer from duty cycle limitations when the number of series connection is large, as will be discussed in the following subsection. Therefore, the need for the transformer in the Ćuk converter is justified, although comparative analysis is necessary to determine the best topology to achieve sufficient performance at reasonable size for a given application. The isolated Ćuk converter-based equalizer is focused in the following sections.

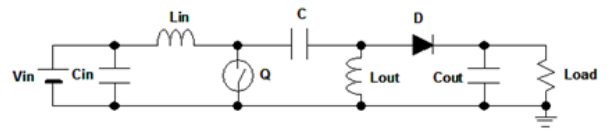

(a)

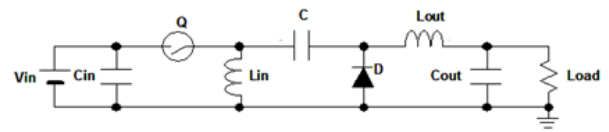

(b)
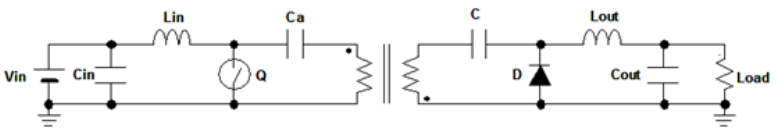

(c)

Figure 5. Traditional buck-boost converters that can be used as the basic topology for single-switch cell voltage equalizers. (a) SEPIC, (b) Zeta, and (c) isolated Ćuk converters.

The derived isolated Ćuk converter-based single-switch equalizer for four cells connected in series is shown in Fig. 6. The circuit consisting of $C_{i n}, L_{i n}, Q, C_{a}$, transformer, $C_{3}, D_{3}$, and $L_{3}$ is identical to the circuit shown in Fig. 5(c), while the circuit consisting of $\mathrm{C}_{\mathrm{i}}-\mathrm{D}_{\mathrm{i}}-\mathrm{Li}(\mathrm{i}=1 \ldots 4)$ is multi-stacked to the isolated Ćuk converter. Hence, the derived equalizer can be regarded as multi-stacked Ćuk converters.

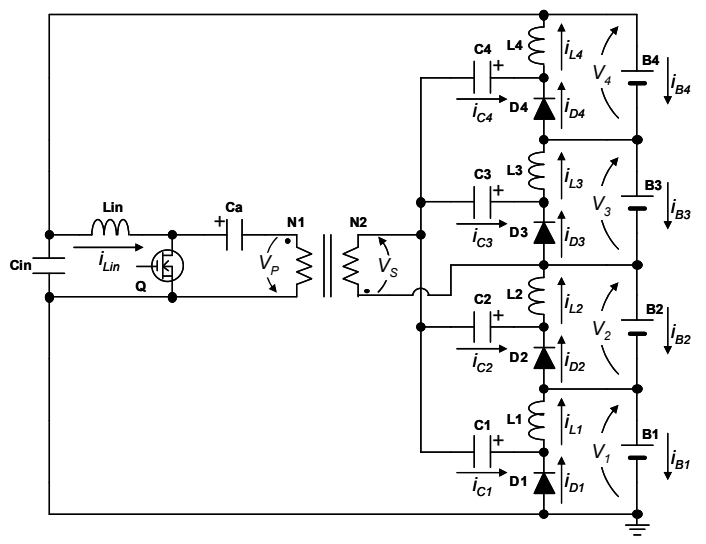

Figure 6. Single-switch cell voltage equalizer based on isolated Ćuk converter. 
The required number of switches is only one; thus, reducing the circuit complexity significantly when compared with conventional equalizers that need numerous switches proportional to the number of series connections, as explained in the previous section. In addition, a multi-winding transformer is not necessary, and the number of series connections can be arbitrarily extended by stacking the circuit consisting of $\mathrm{C}_{\mathrm{i}}-\mathrm{Di}_{\mathrm{i}}-\mathrm{Li}$. Therefore, in addition to the reduced circuit complexity, the single-switch equalizer offers a good modularity as well. Furthermore, as will be mathematically indicated, feedback control is not necessary when it is operated in discontinuous conduction mode (DCM), further simplifying the circuitry by removing the feedback control loop.

\subsection{Operation analysis}

\subsubsection{Operation under voltage-balanced condition}

Traditional buck-boost converters, including the isolated Ćuk converter, operate in either continuous conduction mode (CCM) or DCM. The boundary between CCM and DCM is the discontinuity of the diode current during the off-period. Although ripple currents of inductors tend to be large in DCM, currents in the circuit can be limited under desired levels without feedback control, as will be mathematically indicated later. The following analysis focuses on DCM operation. Key operation waveforms and current flow directions in DCM under the voltage-balanced condition are shown in Figs. 7 and 8 , respectively. The fundamental operation is similar to the traditional isolated Ćuk converter, and the DCM operation can be divided into three periods: $T_{\text {on }}$, $T_{\text {off-a }}$, and $T_{\text {off-b. }}$.

Under a steady-state condition, average voltages of inductors and transformer windings are zero, and hence, the average voltages of $\mathrm{C}_{1}-\mathrm{C}_{4}$ and $\mathrm{C}_{\mathrm{a}}, V_{\mathrm{C} 1}-V_{\mathrm{C} 4}$ and $V_{\mathrm{Ca}}$, can be expressed as

$$
\left\{\begin{array}{l}
V_{C 1}=-V_{2} \\
V_{C 2}=0 \\
V_{C 3}=V_{3} \\
V_{C 4}=V_{3}+V_{4} \\
V_{C a}=V_{1}+V_{2}+V_{3}+V_{4}
\end{array},\right.
$$

where $V_{1}-V_{4}$ are the voltages designated in Fig. 6.

During Ton period, as shown in Fig. 8(a), all the inductors are energized and their currents increase linearly. When $\mathrm{Q}$ is turned off, $T_{\text {off- } a}$ period begins and diodes start to conduct, as shown in Fig. 8(b). As the inductors release stored energies, the inductor currents as well as the diode currents decrease linearly. When the diode currents fall to zero, period $T_{\text {off }-b}$ begins. In this period, all the currents in the equalizer are constant because the voltages across inductors are zero. 


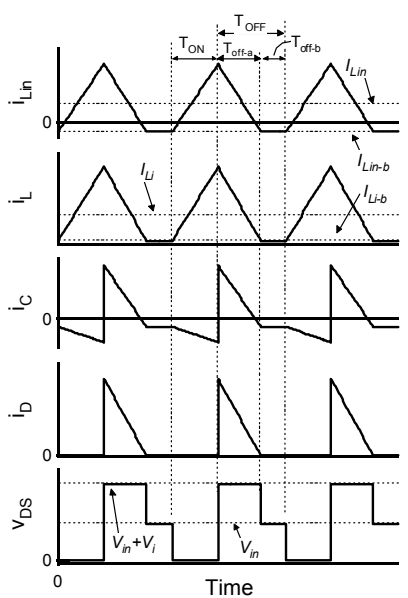

Figure 7. Key operation waveforms of isolated Ćuk converter-based single-switch equalizer under a voltage-balanced condition.

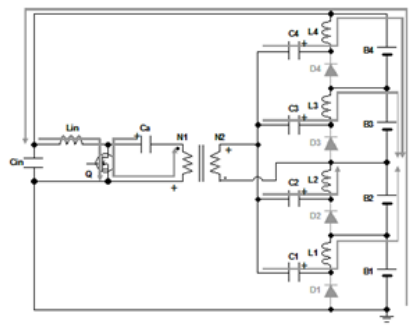

(a)

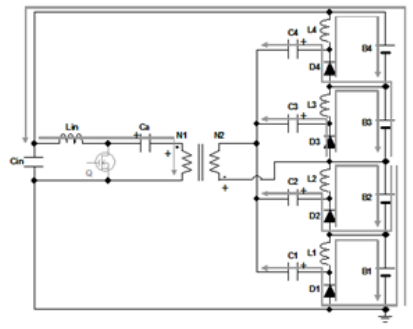

(b)

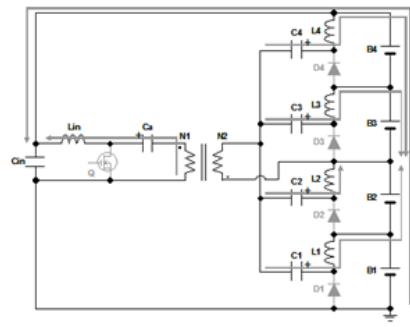

(c)

Figure 8. Current flow directions during periods (a) $T_{o n}$, (b) $T_{\text {off } f \text {, }}$ and (c) $T_{\text {off }-b}$ under a voltage-balanced condition.

The voltage-time product of inductors under a steady-state condition is zero, yielding

$$
\left\{\begin{array}{l}
D\left(V_{S}+V_{C 1}+V_{2}\right)=D_{a}\left(V_{1}+V_{D}\right) \\
D\left(V_{S}+V_{C 2}\right)=D_{a}\left(V_{2}+V_{D}\right) \\
D\left(V_{S}+V_{C 3}-V_{3}\right)=D_{a}\left(V_{3}+V_{D}\right) \\
D\left(V_{S}+V_{C 4}-V_{3}-V_{4}\right)=D_{a}\left(V_{4}+V_{D}\right)
\end{array}\right.
$$

where $D$ and $D_{a}$ are the duty ratio of $T_{\text {on }}$ and $T_{\text {off-a }}$, respectively, $V_{D}$ is the forward voltage of diodes, and $V_{s}$ is the transformer secondary voltage designated in Fig. 6 expressed as

$$
V_{S}=\frac{V_{P}}{N}=\frac{V_{1}+V_{2}+V_{3}+V_{4}}{N}=\frac{V_{\text {in }}}{N},
$$

where $N$ is the transformer turn ratio. From Eqs. (1) and (2), 


$$
V_{i}=\frac{D}{D_{a}} V_{S}-V_{D^{\prime}}
$$

where $i=1 \ldots 4$. This equation means that the equalizer produces the uniform output voltages to the cells, and all the cell voltages can eventually become uniform.

In order for the equalizer to operate in DCM, Toff-b period must exist, meaning $D_{a}<(1-D)$. From Eq. (4), the critical duty cycle to ensure DCM operation, $D_{\text {critical, }}$, is given by

$$
D_{\text {critical }}<\frac{V_{i}+V_{D}}{V_{S}+V_{i}+V_{D}}
$$

Eqs. (3) and (5) imply that without the variable $N$, as $V_{\text {in }}$ increases, $D$ must be lowered for a given value of $V_{i}$. In other words, the duty cycle limitation confronts when the number of series connection is large. On the other hand, with the introduction of the transformer, the issue on the duty cycle limitation can be overcome by properly determining $N$.

According to Fig. 7, the average currents of $\mathrm{Li}$ and $\mathrm{Lin}, I_{L i}$ and $I_{L i n}$, are expressed as

$$
\left\{\begin{array}{l}
I_{L i}=\left(D+D_{a}\right) \frac{V_{S} D T_{S}}{2 L_{i}}+I_{L i-b} \\
I_{L i n}=\left(D+D_{a}\right) \frac{V_{S} D T_{S}}{2 L_{i n}}+I_{L i n-b}
\end{array},\right.
$$

where $T_{S}$ is the switching period, and $I_{L i-b}$ and $I_{L i n-b}$ are the currents flowing through $\mathrm{Li}_{\mathrm{i}}$ and Lin, respectively, during period $T_{\text {off- } b}$ as designated in Fig. 7. Assuming that impedances of $C_{1}-C_{4}$ are equal, $i_{C 1}-i_{C 4}$ as well as $I_{L 1-b}-I_{L 4-b}$ can be uniform, as expressed by

$$
N I_{L i n-b}=-I_{L 1-b}-I_{L 2-b}-I_{L 3-b}-I_{L 4-b}=-4 I_{L i-b} \text {. }
$$

The average current of $\mathrm{C}_{\mathrm{i}}, I_{\mathrm{C}}$, is expressed as

$$
I_{C i}=I_{L i-b}+D \frac{V_{S} D T_{S}}{2 L_{i}}-D_{a} \frac{N^{2} V_{S} D T_{S}}{2 \cdot 4 L_{i n}}=0
$$

From Eqs. (6)-(8),

$$
\frac{I_{L i}}{I_{\text {Lin }}}=\frac{N D_{a}}{4 D} .
$$

With $I_{C i}=0$, Kirchhoff's current law in Fig. 6 yields

$$
I_{L i}=I_{D i}
$$

where $I_{D i}$ is the average current of $D_{i}$. From Figs. 7 and $8(b), I_{D i}$ is expressed as 


$$
I_{D i}=D_{a}\left(\frac{V_{S} D T_{S}}{2 L_{i}}+\frac{N^{2} V_{S} D T_{S}}{2 \cdot 4 L_{\text {in }}}\right)=\frac{V_{S} D D_{a} T_{S}}{2}\left(\frac{4 L_{\text {in }}+N^{2} L_{i}}{4 L_{i n} L_{i}}\right) .
$$

Substituting Eqs. (10) and (11) into Eq. (9) produces

$$
I_{\text {Lin }}=\frac{V_{S} D^{2} T_{S}}{2 N}\left(\frac{4 L_{\text {in }}+N^{2} L_{i}}{L_{\text {in }} L_{i}}\right) .
$$

Eqs. (10)-(12) imply that currents in the equalizer under a voltage-balanced condition can be limited under a desired level as long as a variation range of $V_{S}$ is known. In Eq. (12), for example, $V_{s}$ is variable and $D$ is determinable, while others are fixed values, and hence, with a known variation range of $V_{S}$, ILin can be designed limited under the desired level by properly determining $D$. $I_{L i}$ and $I_{D i}$ (that can be expressed by Eqs. (10) and (11)) can be similarly designed because $D_{a}$ is a predictable variable given by Eq. (4). Thus, the currents in the equalizer operating in DCM can be limited under desired levels even in fixed duty cycle operations, and feedback control is not necessary for the single-switch equalizer, further simplifying the circuit by eliminating the feedback control loop.

\subsubsection{Operation under voltage-imbalanced condition}

As expressed by Eq. (4), the single-switch equalizer inherently produces the uniform output voltages to the cells. This characteristic implies that in the case where voltages of cells are imbalanced, the currents from the equalizer tend to concentrate to a cell having the lowest voltage. Fig. 9 shows the key operation waveforms under a voltage-imbalanced condition. Asterisks added to the symbols in Fig. 9 correspond to the cell with the lowest voltage, $\mathrm{B}^{*}$. As shown in Fig. 9, when there is voltage imbalance, only $i_{D^{*}}$ flows, whereas the other diode currents $\left(i_{D i}\right)$ are zero for the entire periods. Since all the currents concentrate to $\mathrm{D}^{*}$, the average current of $D^{*}$ is obtained by transforming Eq. (11) as

$$
I_{D^{*}}=D_{a}\left(\frac{4 V_{S} D T_{S}}{2 L_{i}}+\frac{N^{2} V_{S} D T_{S}}{2 L_{i n}}\right)=\frac{V_{S} D D_{a} T_{S}}{2}\left(\frac{4 L_{i n}+N^{2} L_{i}}{L_{i n} L_{i}}\right),
$$

which is fourfold larger than that of Eq. (11). Since $I_{D i}$ is zero under the voltage-imbalanced condition, $I_{L i}$ is also zero according to Eq. (10), although ripples exist. ILin under the voltageimbalanced condition is identical to that under the voltage-balanced condition because $I_{\text {Lin }}$ is independent of cell voltages, as expressed by Eq. (12).

\subsection{Experimental}

\subsubsection{Prototype and its fundamental performance}

A 5-W prototype of the isolated Ćuk converter-based single-switch equalizer was built for 12 cells connected in series, as shown in Fig. 10. Component values are listed in Table 1. 
Cout1-Cout12, which were not depicted in figures for the sake of simplicity, are smoothing capacitors connected to the cells in parallel. The RCD snubber was added at the primary winding in order to protect the switch from surge voltages generated by the transformer leakage inductance. The prototype was operated with a fixed $D=0.3$ at $f=150 \mathrm{kHz}$.

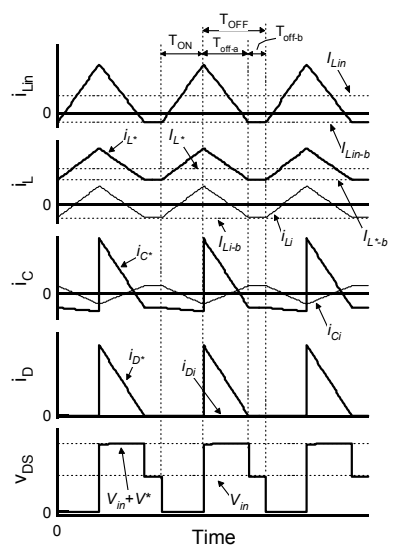

Figure 9. Key operation waveforms under a voltage-imbalanced condition.

The experimental setup for power conversion efficiency measurement is shown in Fig. 11. The tap $\mathrm{Y}$ and $\mathrm{X}$ in Fig. 11 were selected to emulate the voltage-balanced and -imbalanced $\left(V_{1}<V_{i}(i=2 \ldots 12)\right)$ conditions, respectively. The external power supply, $V_{\text {ext, }}$ was used, and the input and output of the equalizer were broken at point $\mathrm{Z}$ in order to measure efficiencies. The efficiencies were measured by changing the ratio of $V_{1} / V_{\text {in }}$ between approximately $1 / 12$ and $1 / 16$. During the efficiency measurement, cells were removed and only smoothing capacitors (Cout1-Cout12) were used to sustain the voltages of $V_{1}-V_{12}$.

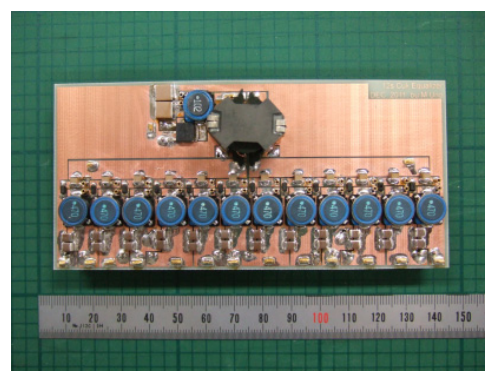

Figure 10. Photograph of a 5-W prototype of the isolated Ćuk converter-based single-switch cell voltage equalizer for 12 cells connected in series.

The measured power conversion efficiencies and output power characteristics as a function of $V_{1}$ are shown in Fig. 12. The efficiencies increased with $V_{1}$ because the diode voltage drop represented a lesser portion of the output voltage (i.e., $V_{1}$ ). The efficiencies under the voltage-balanced condition were higher than those under the voltage-imbalanced condition; 
the peak efficiencies under the voltage-balanced and -imbalanced conditions were approximately $70 \%$ and $65 \%$, respectively. The lower efficiencies under the voltageimbalanced condition were due to the current concentration to $\mathrm{C}_{1}, \mathrm{D}_{1}$, and $\mathrm{L}_{1}$, which caused increased Joule losses in resistive components.

\begin{tabular}{cc}
\hline Component & Value \\
\hline \hline $\mathrm{C}_{\mathrm{in}}$ & Ceramic Capacitor, $20 \mu \mathrm{F}$ \\
\hline $\mathrm{C}_{\mathrm{a}}$ & Ceramic Capacitor, $22 \mu \mathrm{F}$ \\
\hline $\mathrm{C}_{\text {out } 1}-\mathrm{C}_{\text {aut } 12}$ & Ceramic Capacitor, $200 \mu \mathrm{F}$ \\
\hline $\mathrm{C}_{1}-\mathrm{C}_{12}$ & Ceramic Capacitor, $22 \mu \mathrm{F}$ \\
\hline $\mathrm{L}_{\mathrm{in}}$ & $1 \mathrm{mH}$ \\
\hline $\mathrm{L}_{1}-\mathrm{L}_{12}$ & $47 \mu \mathrm{H}$ \\
\hline Transfomer & $N_{1}: N_{2}=24: 4, L_{k g}=8.7 \mu \mathrm{H}, L_{m g}=2.03 \mathrm{mH}$ \\
\hline $\mathrm{Q}$ & $\mathrm{N}-\mathrm{Ch}$ MOSFET, IRFR13N20D, $R_{o n}=235 \mathrm{~m} \Omega$ \\
\hline $\mathrm{D}_{1}-\mathrm{D}_{12}$ & Schottky Diode, CRS08, $V_{D}=0.36 \mathrm{~V}$ \\
\hline RCD Snubber & $R=2.2 \mathrm{k} \Omega, C=470 \mathrm{pF}$ \\
\hline
\end{tabular}

Table 1. Component values used for the prototype.

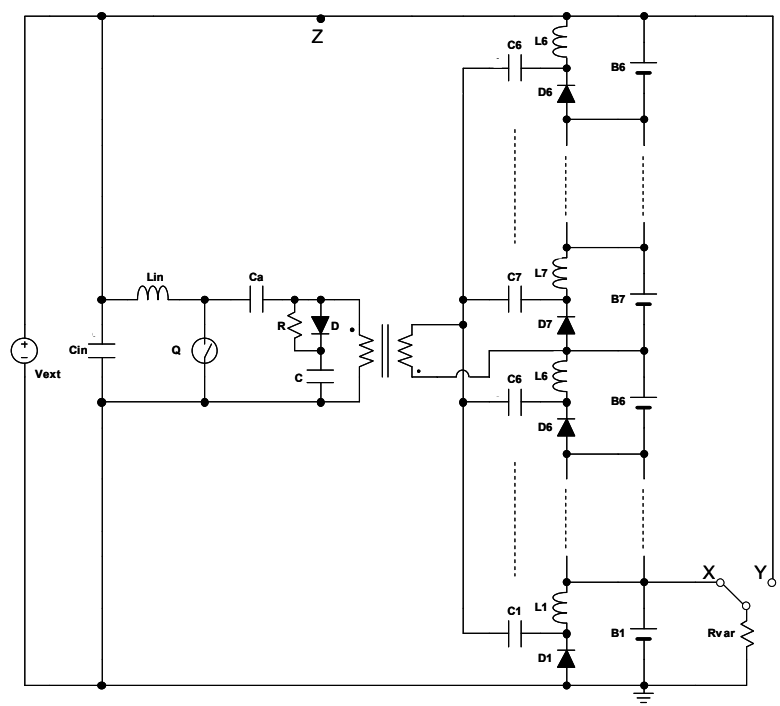

Figure 11. Experimental setup for efficiency measurement.

Figs. 13(a) and (b) show typical operation waveforms measured under the voltage-balanced and -imbalanced conditions, respectively. Under the voltage-balanced condition, as shown in Fig. 13(a), all the inductor currents were uniform, although the oscillations caused by interactions between inductors and parasitic capacitance of the MOSFET were observed. Under the voltage-imbalanced condition, $i_{L 2}-i_{L 12}$ were uniform and their averages were zero, whereas only $i_{L 1}$ showed an average higher than zero because of the current concentration. 


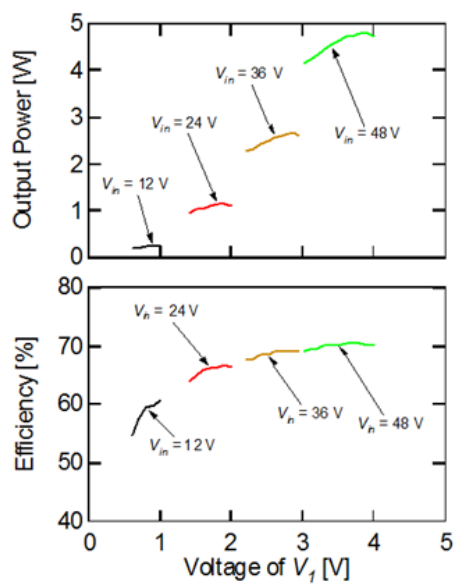

(a)

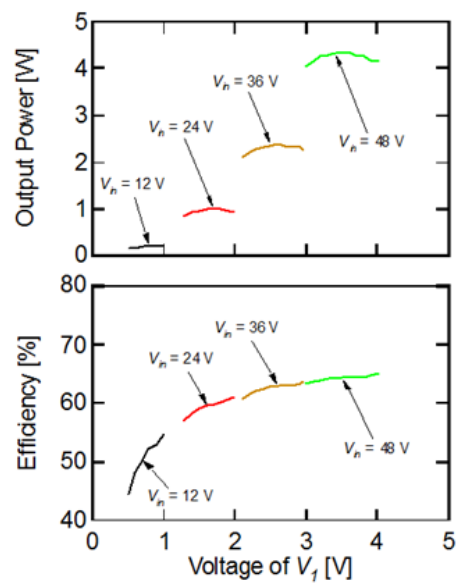

(b)

Figure 12. Measured power conversion efficiencies and output powers as a function of $V_{1}$ under (a) voltage-balanced and (b) -imbalanced conditions.

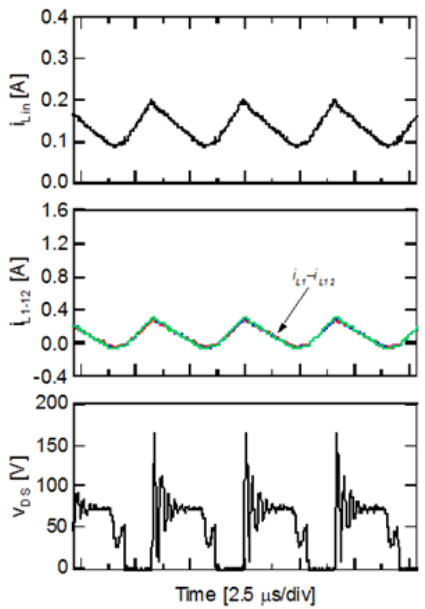

(a)

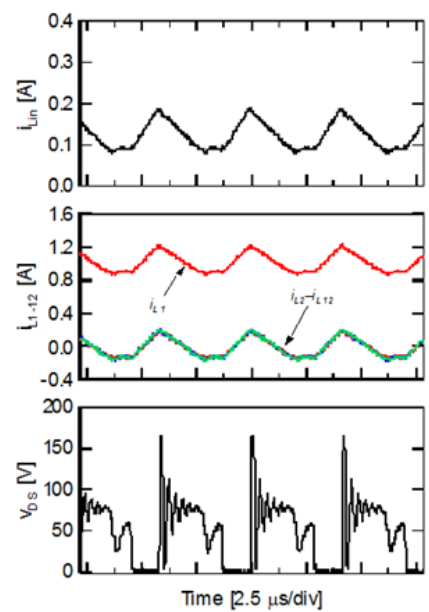

(b)

Figure 13. Measured waveforms under (a) voltage-balanced and (b) -imbalanced conditions.

\subsubsection{Equalization}

The experimental equalization test was performed for 12-series SCs with a capacitance of $500 \mathrm{~F}$ at a rated charge voltage of $2.5 \mathrm{~V}$. The voltages of SCs were initially imbalanced between $0.85-2.5 \mathrm{~V}$. The resultant equalization profiles are shown in Fig. 14(a). As the equalizer redistributed energies from the series connection to cells with low voltages, voltages of cells with low initial voltages increased while those with high initial voltages 
decreased. The voltage imbalance was gradually eliminated as time elapsed, and the standard deviation of cell voltages eventually decreased down to approximately $7 \mathrm{mV}$ at the end of the experiment; thus, demonstrating the equalizer's equalization performance. The cell voltages kept decreasing even after the voltage imbalance disappeared. This decrease was due to the power conversion loss in the equalizer. After the cell voltages were balanced, the energies of the cells were meaninglessly circulated by the equalizer, and therefore, the equalizer should be disabled after cell voltages are sufficiently balanced in order not to waste the stored energies of cells.

Another experimental equalization was performed for 12-series lithium-ion cells with a capacity of $2200 \mathrm{mAh}$ at a rated charge voltage of $4.2 \mathrm{~V}$. The state of charges (SOCs) of the cells were initially imbalanced between $0 \%-100 \%$. The experimental results are shown in Fig. 14(b). Although the resultant profiles were somewhat elusive because of the nonlinear characteristics of the lithium-ion chemistry, the voltage imbalance was successfully eliminated, and all the cell voltage converged to a uniform voltage level.

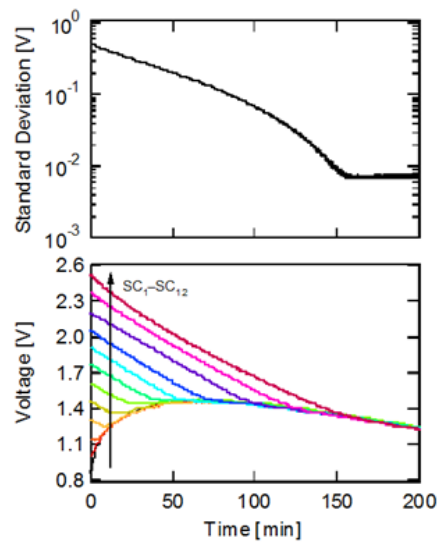

(a)

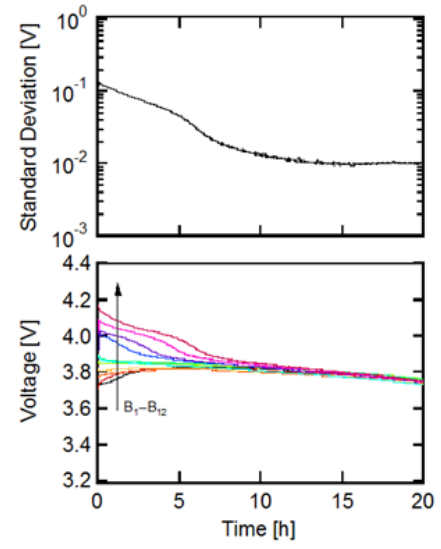

(b)

Figure 14. Experimental profiles of 12 series-connected (a) SCs and (b) lithium-ion cells equalized by the isolated Ćuk converter-based single-switch equalizer.

\section{Double-switch resonant cell voltage equalizer using a voltage multiplier}

\subsection{Circuit description and major benefits}

The double-switch resonant equalizer is essentially a combination of a conventional series resonant inverter and a voltage multiplier, shown in Figs. 15(a) and (b), respectively. The voltage multiplier shown in Fig. 15(b) is an example circuit that can produce a 4 times higher voltage than the amplitude of the input. The voltages of the stationary capacitors $\mathrm{C}^{\prime}{ }_{1}-$ $\mathrm{C}_{4}^{\prime}$ automatically become uniform as the amplitude of the input square wave under a steady-state condition (when diode voltage drops are neglected). Detailed operation 
analyses on both the resonant inverter and the voltage multiplier are separately made in the following section.

By combining the series-resonant inverter and the voltage multiplier, the double-switch equalizer can be synthesized as shown in Fig. 16. The leakage inductance of the transformer is used as the resonant inductor, Lr. The magnetizing inductance of the transformer is not depicted in Fig. 16 for the sake of simplicity. The stationary capacitors $C^{\prime}{ }_{1}-C^{\prime} 4$ in the voltage multiplier in Fig. 15(b) are replaced with energy storage cells $B_{1}-B_{4}$.

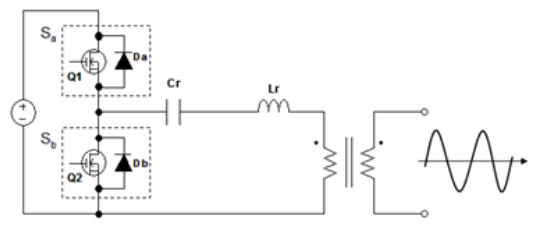

(a)

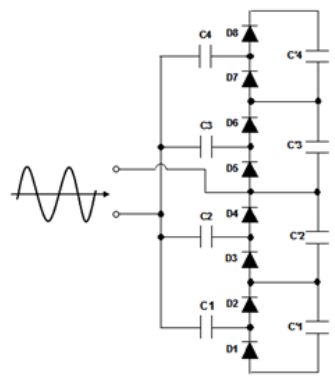

(b)

Figure 15. (a) Series-resonant inverter and (b) 4x-voltage multiplier.

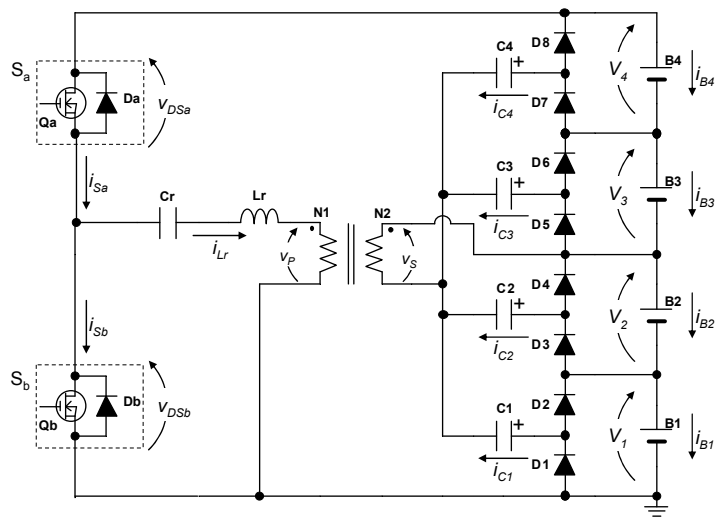

Figure 16. Double-switch series-resonant equalizer using voltage multiplier.

The required number of switches and magnetic components are only two and one, respectively, and hence, the circuit complexity as well as the size and cost of the circuit can be significantly reduced when compared with conventional equalizers, which need multiple switches and/or magnetic components in proportion to the number of series connections. In addition, the proposed resonant equalizer can be configured without a multi-winding transformer, and the number of series connections can be readily extended by stacking a capacitor and diodes, thus offering a good modularity (or extendibility). As mathematically explained in the following analysis, feedback control is not necessarily needed to limit 
currents under the desired current levels, and therefore, the circuit can be further simplified by removing the feedback control loop.

Although the series-resonant inverter with a transformer is used for the proposed equalizer, other types of resonant inverters, such as parallel-, series-parallel-, and LLC-resonant inverters, can be used instead, and may even offer better performance.

\subsection{Operation analysis}

\subsubsection{Fundamental operation}

Similar to traditional resonant inverters, the double-switch resonant equalizer is operated at the switching frequency $f$ higher than the resonant frequency, $f_{r}$, above which the seriesresonant circuit consisting of $\mathrm{Lr}$ and $\mathrm{C}_{\mathrm{r}}$ represents an inductive load. The key operation waveforms at $f>f_{r}$ are shown in Fig. 17, and $f_{r}$ is given by

$$
f_{r}=\frac{1}{2 \pi \sqrt{L_{r} C_{r}}},
$$

where $L_{r}$ is the inductance of the resonant inductor $\mathrm{Lr}_{\text {, }}$ and $C_{r}$ is the capacitance of the resonant capacitor $\mathrm{C}_{\mathrm{r}}$. MOSFETs $\mathrm{Q}_{\mathrm{a}}$ and $\mathrm{Q}_{\mathrm{b}}$ are complementarily operated with a fixed duty cycle slightly less than $50 \%$ in order to provide adequate dead times to prevent a shortthrough current. Above $f_{r}$, the current of the resonant circuit $i_{L r}$ lags behind the fundamental component of the voltage $v_{D S b}$, which corresponds to the input voltage for the resonant circuit, and $\mathrm{Q}_{\mathrm{a}}$ and $\mathrm{Q}_{\mathrm{b}}$ are turned on at zero-voltage.

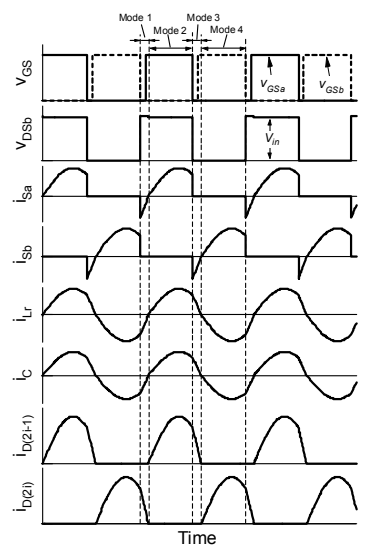

Figure 17. Key operation waveforms of resonant equalizer above resonant frequency $\left(f>f_{r}\right)$.

The operation of the series-resonant equalizer can be divided into four modes: Mode 1-4, and the current flow directions under a voltage-balanced condition during each mode are shown in Fig. 18. In Mode 1, the current of the resonant circuit, $i_{L r}$, flows through the antiparallel diode of $\mathrm{S}_{\mathrm{a}}, \mathrm{D}_{\mathrm{a}}$, toward the series connection of $\mathrm{B}_{1}-\mathrm{B}_{4}$, and the energy transfer 
capacitors in the voltage multiplier, $C_{i}(i=1 \ldots 4)$, discharge through even-numbered diodes, $\mathrm{D}_{(2 \mathrm{i})}$, as shown in Fig. 18(a). Before isa reaches zero, the gate signal for $\mathrm{Q}_{\mathrm{a}}, v_{G S a}$, is applied. Since the voltage across $\mathrm{Q}_{\mathrm{a}}$, vDSa, is zero at this moment, $\mathrm{Q}_{\mathrm{a}}$ is turned on at zero-

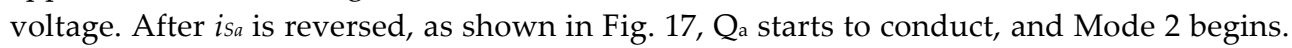
In Mode 2, the resonant circuit is energized by the series connection of $B_{1}-B_{4}$, and $C_{i}$ is charged via odd-numbered diodes, $\mathrm{D}_{(2 \mathrm{i}-1)}$. As $\mathrm{Q}_{\mathrm{a}}$ is turned off, the current is diverted from $\mathrm{Q}_{\mathrm{a}}$ to the anti-parallel diode of $\mathrm{S}_{\mathrm{b}}, \mathrm{D}_{\mathrm{b}}$, and Mode 3 begins. $\mathrm{C}_{\mathrm{i}}$ is still being charged. The gate signal for $\mathrm{Q}_{\mathrm{b}}, v_{G S b}$, is applied and $\mathrm{Q}_{\mathrm{b}}$ is turned on at zero-voltage, before the current of $\mathrm{S}_{\mathrm{b}}, i_{s b}$, is reversed. As $i_{s b}$ reaches zero, the operation shifts to Mode 4, in which $\mathrm{C}_{\mathrm{i}}$ discharges through $\mathrm{D}_{(2 \mathrm{i})}$. When $\mathrm{Q}_{\mathrm{b}}$ is turned off, the current is diverted from $\mathrm{Q}_{b}$ to $\mathrm{D}_{\mathrm{a}}$, and the operation returns to Mode 1 . Thus, similar to the conventional resonant inverters, the double-switch resonant equalizer achieves zero-voltage switching (ZVS) operation when $\mathrm{Q}_{\mathrm{a}}$ and $\mathrm{Q}_{\mathrm{b}}$ are turned on.

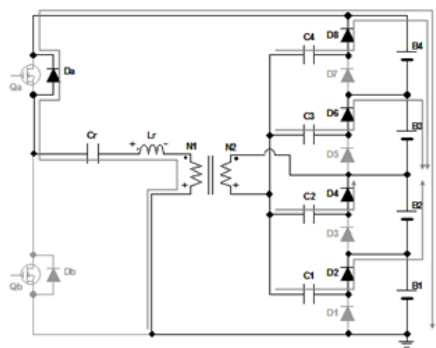

(a)

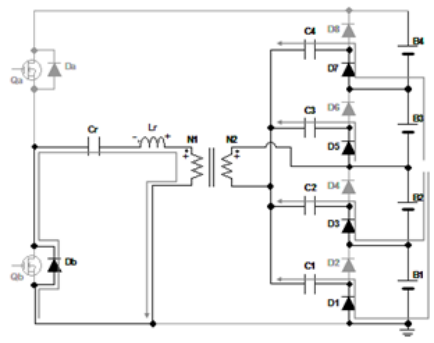

(c)

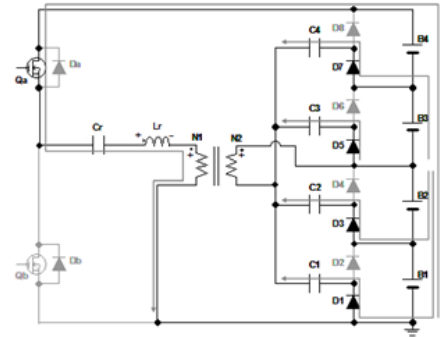

(b)

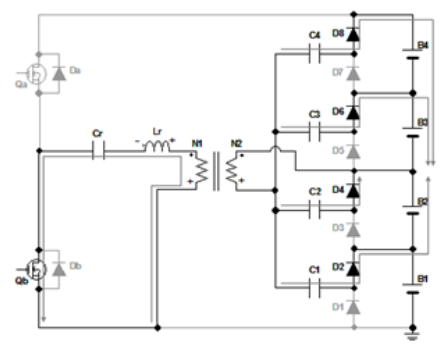

(d)

Figure 18. Current flow directions during Mode (a) 1, (b) 2, (c) 3, and (d) 4.

Repeating the above sequence, energies of the series connection of $\mathrm{B}_{1}-\mathrm{B}_{4}$ are supplied to the resonant inverter, and then are transferred to the voltage multiplier that redistributes the energies to $\mathrm{B}_{1}-\mathrm{B}_{4}$. Thus, the energies of $\mathrm{B}_{1}-\mathrm{B}_{4}$ are redistributed via the resonant inverter and voltage multiplier. Throughout a single switching cycle, $\mathrm{C}_{i}$ as well as $\mathrm{B}_{1}-\mathrm{B}_{4}$ are charged and discharged via $\mathrm{D}_{(2 \mathrm{i}-1)}$ and $\mathrm{D}_{(2 \mathrm{i})}$, and consequently, voltages of $\mathrm{B}_{1}-\mathrm{B}_{4}, V_{1}-V_{4}$, become automatically uniform. The voltage equalization mechanism by the voltage multiplier is discussed in detail in the following subsection. 


\subsubsection{Voltage multiplier}

The peak voltage of $\mathrm{C}_{\mathrm{i}}$ during the time $\mathrm{D}_{(2 \mathrm{i}-1)}$ is on, $V_{\mathrm{CiO}}$, can be expressed as

$$
\left\{\begin{array}{l}
V_{C 1 O}=V_{S-O}-V_{D}-V_{1}-V_{2} \\
V_{C 2 O}=V_{S-O}-V_{D}-V_{2} \\
V_{C 3 O}=V_{S-O}-V_{D} \\
V_{C 4 O}=V_{S-O}-V_{D}+V_{3}
\end{array},\right.
$$

where $V$ s-o is the peak voltage of the transformer secondary winding when $\mathrm{D}_{(2 \mathrm{i}-1)}$ is on, and $V_{D}$ is the forward voltage drop of the diodes. Similarly, the bottom voltages of $C_{i}$ when $D_{(2 i)}$ is on, $V_{C i E}$, are

$$
\left\{\begin{array}{l}
V_{C 1 E}=-V_{S-E}+V_{D}-V_{2} \\
V_{C 2 E}=-V_{S-E}+V_{D} \\
V_{C 3 E}=-V_{S-E}+V_{D}+V_{3} \\
V_{C 4 E}=-V_{S-E}+V_{D}+V_{3}+V_{4}
\end{array},\right.
$$

where $V$ S-E is the bottom voltage of the transformer secondary winding when $\mathrm{D}_{(2 \mathrm{i})}$ is on.

Subtracting Eq. (16) from Eq. (15) yields the voltage variation of $C_{i}$ during a single switching cycle, $\Delta V_{C i}$ :

$$
\Delta V_{C i}=\left(V_{S-O}+V_{S-E}\right)-V_{i}-2 V_{D}
$$

Generally, an amount of charge delivered via a capacitor having a capacitance of $C$, and an equivalent resistance for the charge transfer, $R_{e q}$, are given by

$$
\left\{\begin{array}{l}
Q=I t=C \Delta V \\
\Delta V=\frac{I t}{C}=\frac{I}{C f}=I R_{e q}
\end{array}\right.
$$

where $\Delta V$ is the voltage variation caused by charging/discharging. Substitution of Eq. (18) into Eq. (17) produces

$$
I_{C i} R_{e q i}=\left(V_{S-O}+V_{S-E}\right)-2 V_{D}-V_{i},
$$

where $I_{C i}$ is the average current flowing via $\mathrm{C}_{\mathrm{i}}$.

Eq. (19) yields a dc equivalent circuit of the voltage multiplier, as shown in Fig. 19. All cells, $\mathrm{B}_{1}-\mathrm{B}_{4}$, are tied to a common dc-source $\mathrm{V}_{\mathrm{dc}}$, which provides a voltage of ( $\left.V_{S-O}+V_{s-E}\right)$, via two diodes and one equivalent resistor, Reqi. When $V_{1}-V_{4}$ are balanced, $I_{C 1}-I_{C 4}$ can be uniform as long as $C_{1}-C_{4}$ are designed so that all the equivalent resistances, $R_{e q 1}-R_{e q 4}$, are uniform. In the case of voltage imbalance, the current preferentially flows to the cell(s) having the lowest 
voltage, and its voltage increases more quickly than the others. Eventually, voltages $V_{1}-V_{4}$ automatically reach a uniform voltage level.

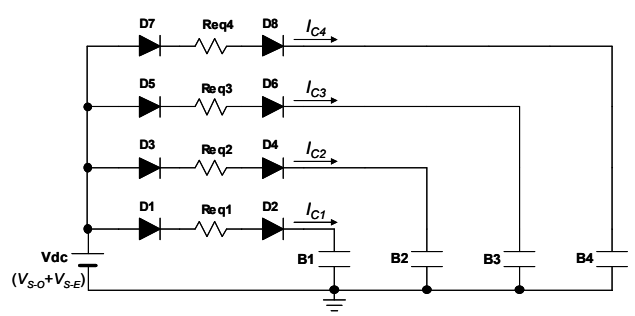

Figure 19. DC equivalent circuit for voltage multiplier.

Current flows in the dc equivalent circuit in Fig. 19 can then be transformed to those in the original circuit shown in Figs. 16 and 18. We consider the case that $V_{1}$ is the lowest and when no currents flow through $R_{\text {eq2 }}-R_{\text {eq4 }}$, as a simple example. Since any current flowing through Reqi represents charging/discharging the capacitor $C_{i}$, as indicated by Eq. (18), no currents in Req2-Req4 mean that no currents flow through $\mathrm{C}_{2}-\mathrm{C}_{4}$ as well as $\mathrm{D}_{3}-\mathrm{D}_{8}$ in the original circuit. Meanwhile, the current from the transformer secondary winding concentrates to $\mathrm{C}_{1}$ and $\mathrm{D}_{1}-\mathrm{D}_{2}$ in the original circuit. Thus, under a voltage-imbalanced condition, currents flow through only the capacitor(s) and diodes that are connected to the cell(s) having the lowest voltage, although practical current distribution tendencies are dependent on Reqi as well as the voltage conditions of $V_{i}$.

\subsubsection{Series-resonant circuit}

The average voltage across a transformer winding throughout a single switching cycle is zero, and the on-duties of $\mathrm{D}_{(2 \mathrm{i}-1)}$ and $\mathrm{D}_{(2 \mathrm{i})}$ are both $50 \%$. Therefore, the average voltages of $\mathrm{C}_{1-}$ $C_{4}, V_{C 1}-V_{C 4}$, can be obtained from Fig. 18, and are expressed as

$$
\left\{\begin{array}{l}
V_{C 1}=-\frac{V_{1}}{2}-V_{2} \\
V_{C 2}=-\frac{V_{2}}{2} \\
V_{C 3}=\frac{V_{3}}{2} \\
V_{C 4}=V_{3}+\frac{V_{4}}{2}
\end{array} .\right.
$$

The Square voltage waves in the resonant circuit are approximated to the sinusoidal fundamental components, as shown in Fig. 20, in which key waveforms of the seriesresonant inverter and their fundamental components are sketched. By assuming that the voltage of $C_{i}$ is constant as $V_{C i}$ throughout a single switching cycle, the voltage of the transformer secondary winding, vs, is 


$$
v_{S}=\left\{\begin{array}{l}
V_{C 1}+V_{1}+V_{2}+V_{D}=V_{C 2}+V_{2}+V_{D}=V_{C 3}+V_{D}=V_{C 4}-V_{3}+V_{D}\left(D_{(2 i-1)} \text { areon }\right) \\
V_{C 1}+V_{2}-V_{D}=V_{C 2}-V_{D}=V_{C 3}-V_{3}-V_{D}=V_{C 4}-V_{3}-V_{4}-V_{D}\left(D_{(2 i)} \text { areon }\right)
\end{array} .\right.
$$

vs is a square wave with an amplitude of $V s$, which is obtained from Eqs. (20) and (21) as

$$
V_{S}=V_{i}+2 V_{D}
$$

The amplitude of the fundamental component of the transformer primary winding, $V_{m-P}$, can be obtained from Eq. (22) with the Fourier transfer,

$$
V_{m-P}=\frac{2}{\pi} N\left(V_{i}+2 V_{D}\right)
$$

Similarly, the amplitude of the fundamental component of $v_{D S b}, V_{m-i n}$, is

$$
V_{m-i n}=\frac{2}{\pi} V_{i n}=\frac{2}{\pi}\left(V_{1}+V_{2}+V_{3}+V_{4}\right) \text {. }
$$

The amplitude of $i_{L r}, I_{m}$, is obtained as

$$
I_{m}=\frac{V_{m-i n}-V_{m-P}}{|Z|}=\frac{V_{m-i n}-V_{m-P}}{\sqrt{\left(\omega L_{r}-\frac{1}{\omega C_{r}}\right)^{2}}} \frac{V_{m-i n}-V_{m-P}}{\sqrt{\left(\frac{\omega}{\omega_{r}}-\frac{\omega_{r}}{\omega}\right)^{2}}},
$$

where $Z_{0}$ is the characteristic impedance of the resonant circuit given by

$$
Z_{0}=\omega_{r} L_{r}=\frac{1}{\omega_{r} C_{r}}
$$

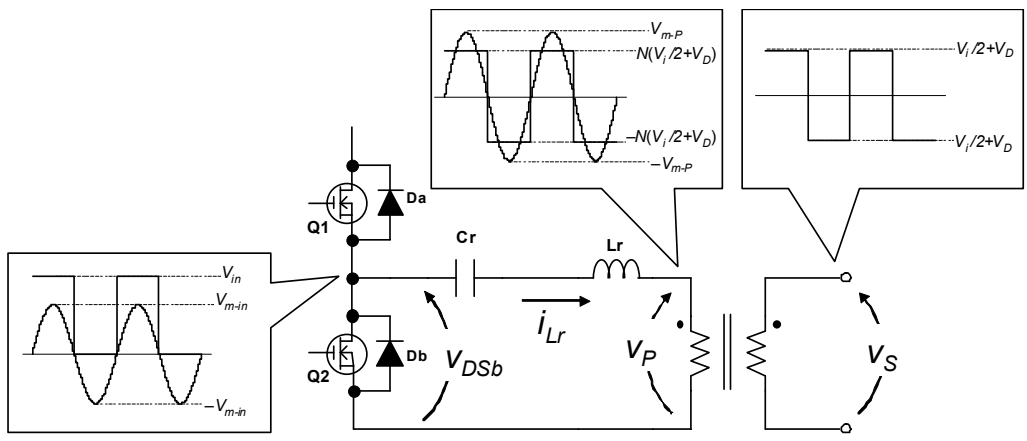

Figure 20. Key waveforms and their fundamental components.

In order for the series-resonant inverter to transfer energies to the voltage multiplier connected to the secondary winding, $V_{m-\text { in }}$ must be higher than $V_{m-P}$. Assuming that the 
number of series connections is four and $V_{1}-V_{4}$ are balanced as $V_{i}$, the criterion of $N$ is obtained from Eqs. (23) and (24), as

$$
N<\frac{4 V_{i}}{V_{i}+2 V_{D}}
$$

Eqs. (23) and (25) indicate that the smaller $N$ is, the larger $I_{m}$ will be, resulting in the larger power transfer from the resonant circuit to the voltage multiplier. Thus, with small $N$, an equalization speed can be accelerated, although it tends to cause increased losses in resistive components in the resonant circuit as well as in the voltage multiplier.

\subsection{Experimental}

\subsubsection{Prototype and its fundamental performance}

A 10-W prototype of the double-switch series-resonant equalizer was built for 8 cells connected in series, as shown in Fig. 21. Table 2 lists the component values used for the prototype. Cout1-Couts are smoothing capacitors connected to cells in parallel (not shown in Fig. 16 for the sake of simplicity). The transformer leakage inductance, $L \mathrm{~kg}$, was used as the resonant inductor $\mathrm{Lr}$, whereas the magnetizing inductance, $L m g$, was designed to be large enough not to influence the series-resonant operation. The prototype equalizer was operated with a fixed $D=0.48$ at a switching frequency of $220 \mathrm{kHz}$.

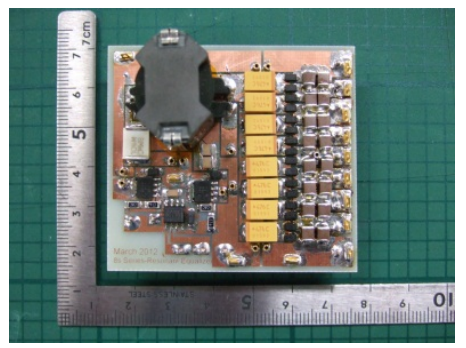

Figure 21. Photograph of a 10-W prototype of the double-switch series-resonant equalizer using a voltage multiplier for 8 cells connected in series.

\begin{tabular}{cc}
\hline Component & Value \\
\hline \hline $\mathrm{C}_{1}-\mathrm{C}_{8}$ & Tantalum Capacitor, $47 \mu \mathrm{F}, 80 \mathrm{~m} \Omega$ \\
\hline $\mathrm{C}_{\text {out } 1}-\mathrm{C}_{\text {out8 }}$ & Ceramic Capacitor, $200 \mu \mathrm{F}$ \\
\hline $\mathrm{C}_{\mathrm{r}}$ & Film Capacitor, $100 \mathrm{nF}$ \\
\hline $\mathrm{Q}_{\mathrm{a}}, \mathrm{Q}_{\mathrm{b}}$ & $\mathrm{N}$-Ch MOSFET, HAT2266H, $\mathrm{R}_{\text {on }}=9.2 \mathrm{~m} \Omega$ \\
\hline $\mathrm{D}_{1}-\mathrm{D}_{16}$ & Schottky Diode, CRS08, $V_{D}=0.36 \mathrm{~V}$ \\
\hline Transformer & $N_{1}: N_{2}=30: 5, L_{k g}=4.7 \mu \mathrm{H}, L_{m g}=496 \mu \mathrm{H}$ \\
\hline
\end{tabular}

Table 2. Component values used for the prototype of the series-resonant equalizer.

The experimental setup for the efficiency measurement for the resonant equalizer is shown in Fig. 22. The efficiency measurement was performed using the intermediate tap and the 
variable resistor in order to emulate the voltage-balanced and -imbalanced conditions. With the tap Y selected, the current flow paths under the voltage-balanced condition are emulated, whereas those under the voltage-imbalanced condition of $V_{1}<V_{i}(i=2 \ldots 12)$ can be emulated by selecting the $\operatorname{tap} X$. The input and the output of the equalizer were separated at the point $Z$ to measure efficiencies. The efficiencies were measured by changing the ratio of $V_{1} / V_{\text {in }}$ between approximately $1 / 8$ and $1 / 20$. Cells were disconnected and only the smoothing capacitors (Cout1Cout8) were used to sustain the voltages of $V_{1}-V_{8}$ in the efficiency measurement.

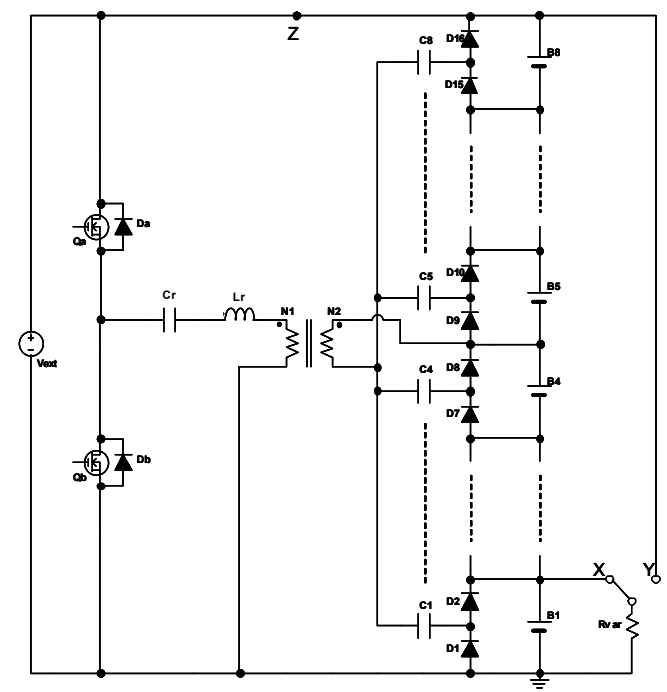

Figure 22. Experimental setup for efficiency measurement for the resonant equalizer.

The measured power conversion efficiencies and output power characteristics as a function of $V_{1}$ are shown in Fig. 23. As $V_{1}$ increased, the efficiencies significantly increased because the diode voltage drop accounted for a lesser portion of the output voltage (i.e., $V_{1}$ ). The measured peak efficiencies under the voltage-balanced and -imbalanced conditions were $73 \%$ and $68 \%$, respectively. The efficiency trends under the voltage-balanced condition were higher than those under the voltage-imbalanced condition. The lower efficiency trend under the voltage-balanced condition can be attributed to increased Joule losses in resistive components in the series-resonant inverter and the voltage multiplier.

Measured waveforms of $i_{L r}$ and $v_{D S b}$ at $V_{i n}=32 \mathrm{~V}$ and $V_{1}=4 \mathrm{~V}$ under the voltage-balanced and -imbalanced conditions are shown in Figs. 24(a) and (b), respectively. The amplitude of $i_{L r}$ under the voltage-balanced condition was slightly greater than that under the voltageimbalanced condition. In the operation analysis made in Section 4.2.3, the voltage across $C_{i}$ was assumed constant and the voltages of transformer windings were treated as square waves. However, in practice, the voltage across $C_{i}$ varies as current flows, and transformer winding voltages are not ideal square waves. Under the voltage-imbalanced condition, as currents in the voltage multiplier concentrated to $C_{1}, V_{m-P}$ tended to increase because of an 
increased voltage variation of $C_{i}$. Consequently, the amplitude of $i_{L r}, I_{m}$, decreased as $V_{m-P}$ increased, as can be understood from Eq. (25).

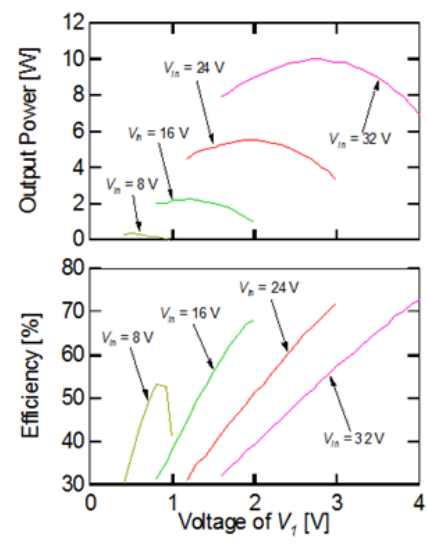

(a)

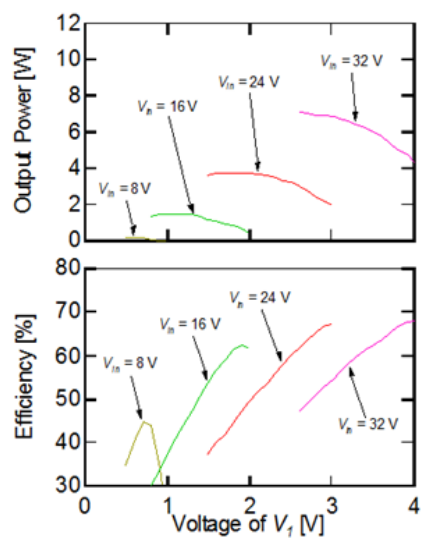

(b)

Figure 23. Measured power conversion efficiencies and output powers of the series-resonant equalizer as a function of $V_{1}$ under (a) voltage-balanced and (b) -imbalanced conditions.

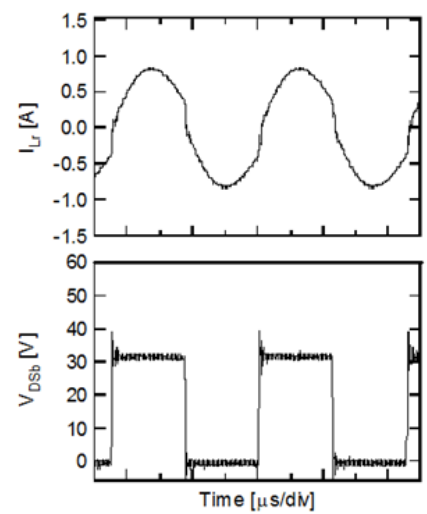

(a)

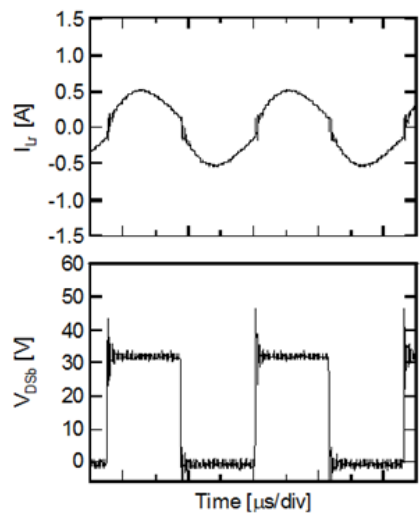

(b)

Figure 24. Measured waveforms under (a) voltage-balanced and (b) -imbalanced conditions.

\subsubsection{Equalization}

The experimental equalization test using the prototype of the series-resonant equalizer was performed for 8-series SCs with a capacitance of $500 \mathrm{~F}$ at a rated charge voltage of $2.5 \mathrm{~V}$. The initial voltages of SCs were imbalanced in the range 1.8-2.5 V. The results of the equalization test are shown in Fig. 25(a). The cell voltages with a high initial voltage decreased, while those with a low initial voltage increased by the energy redistribution mechanism. The voltage imbalance gradually disappeared, and the standard deviation of 
the cell voltages eventually decreased down to approximately $4 \mathrm{mV}$ at the end of the equalization test. The cell voltages were almost completely balanced, and hence, the equalization performance of the series-resonant equalizer was demonstrated.
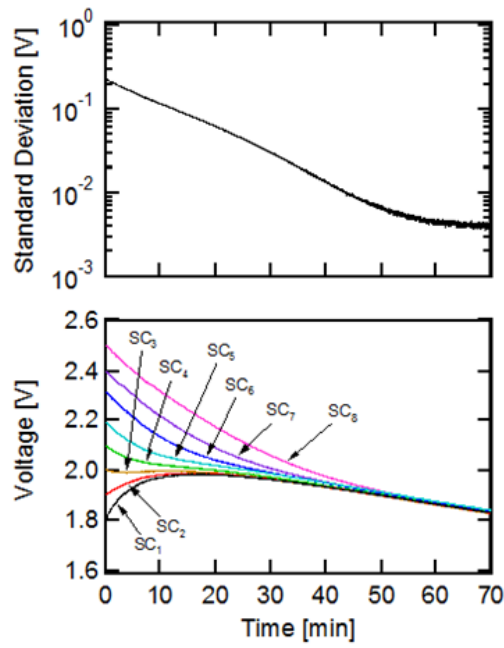

(a)
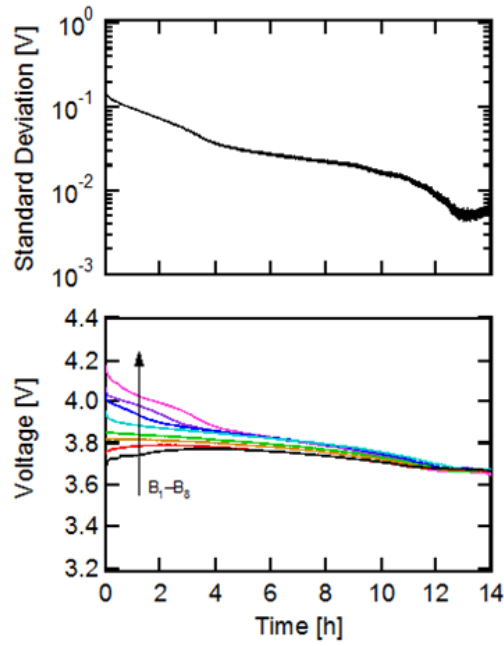

(b)

Figure 25. Experimental profiles of 8 series-connected (a) SCs and (b) lithium-ion cells equalized by the series-resonant equalizer.

A similar experimental equalization was performed for 8-series lithium-ion cells with a capacity of $2200 \mathrm{mAh}$ at a rated charge voltage of $4.2 \mathrm{~V}$. The initial SOCs of the cells were imbalanced between $0 \%-100 \%$. The measured equalization profiles are shown in Fig. 25(b). Despite the nonlinear characteristics of lithium-ion cells, the standard deviation of the cell voltages gradually decreased, and the voltage imbalance was successfully eliminated.

\section{Comparison with conventional equalizers}

The presented single- and double-switch equalizers are compared with conventional equalizers in terms of the number of required power components in Table 3, where $n$ is the number of series connections of cells. Obviously, the passive dissipative equalizers using resistors or diodes are the simplest topology, although they are neither efficient nor practical as mentioned in Section 2.1. Except for the equalizers using a multi-winding transformer, the required number of switches in conventional nondissipative equalizers is proportional to the number of series connections, and therefore, the circuit complexity tends to significantly increase for applications requiring a large number of series connections. Although the equalizers using a multi-winding transformer need only one or two switches, the need of a multi-winding transformer is considered as their major drawback because of the requirement for strict parameter matching among multiple secondary windings, resulting in design difficulty and poor modularity. 


\begin{tabular}{|c|c|c|c|c|c|c|c|}
\hline \multicolumn{2}{|c|}{ Topology } & \multirow{2}{*}{\begin{tabular}{c|} 
Switch \\
- \\
\end{tabular}} & \multirow{2}{*}{\begin{tabular}{|c|} 
Resistor \\
$n$
\end{tabular}} & \multicolumn{2}{|c|}{\begin{tabular}{|l|l|} 
Inductor & Capacitor \\
\end{tabular}} & \multirow{2}{*}{$\begin{array}{c}\text { Diode } \\
-\end{array}$} & \multirow{2}{*}{$\begin{array}{c}\text { Transformer } \\
- \\
\end{array}$} \\
\hline \multirow{3}{*}{ Dissipative Equalizer } & Resistor & & & - & - & & \\
\hline & Zener Diode & - & - & - & - & $n$ & - \\
\hline & Active Shunting & $n$ & $n$ & - & - & - & - \\
\hline \multirow{2}{*}{$\begin{array}{c}\text { Induvidual Cell } \\
\text { Equalizer }\end{array}$} & Switched Capacitor & $2 n$ & - & - & $n-1$ & - & - \\
\hline & Buck-Boost Converter & $2(n-1)$ & - & $n-1$ & - & - & - \\
\hline \multirow{2}{*}{$\begin{array}{l}\text { Multi-Winding } \\
\text { Transformer-Based }\end{array}$} & Flyback Converter & 1 & - & - & - & $n$ & 1 (n+1 windings) \\
\hline & Forward Converter & 2 & - & - & - & $n+2$ & $1(n+1$ windings $)$ \\
\hline \multirow{2}{*}{$\begin{array}{c}\text { Single Converter with } \\
\text { Selection Switches }\end{array}$} & Flying Capacitor & $2 n$ & - & - & 1 & - & - \\
\hline & Flyback Converter & $2 n+1$ & - & - & 1 & 1 & 1 \\
\hline \multicolumn{2}{|c|}{ Single-Switch Equalizer (Isolated Ćuk-Based) } & 1 & - & $n+1$ & $n+1$ & $n$ & 1 \\
\hline \multicolumn{2}{|c|}{ Double-Switch Series-Resonant Equalizer } & 2 & - & $(1)^{*}$ & $n+1$ & $2 n$ & 1 \\
\hline
\end{tabular}

* Inductor is not necessary when leakage inductance of the transformer is used as a resonant inductor (Smoothing Capacitors are excluded)

Table 3. Comparison in terms of required number of power components.

On the other hand, the single-switch equalizer using multi-stacked buck-boost converters (isolated Ćuk converter-based) can operate with a single switch, and therefore, the circuit complexity can be significantly reduced when compared with conventional equalizers that require many switches in proportion to the number of series connections. In addition, since a multi-winding transformer is not necessary and the number of series connections can be readily arbitrary extended by stacking a circuit consisting of $\mathrm{L}, \mathrm{C}$, and D. A drawback of this single-switch equalizer is the need of multiple inductors, with which the equalizer is prone to be bulky and costly as the number of the series connections increases.

The double-switch resonant equalizer using a voltage multiplier is able to operate with two switches and a single transformer (in the case that the leakage inductance of the transformer is used as a resonant inductor). In addition to the reduced number of switches, the required number of magnetic components is only one, and hence, the resonant equalizer achieves simplified circuitry coupled with a reduction in size and cost when compared with those requiring multiple magnetic components. The modularity of the resonant equalizer is also good; by adding $\mathrm{C}$ and $\mathrm{D}$, the number of series connections can be arbitrarily extended.

\section{Conclusions}

Cell voltage equalizers are necessary in order to ensure years of safe operation of energy storage cells, such as SCs and lithium-ion cells, as well as to maximize available energies of cells. Although various kinds of equalization techniques have been proposed, demonstrated, and implemented, the requirement of multiple switches and/or a multi-winding transformer in conventional equalizers is not desirable; the circuit complexity tends to significantly increase with the number of switches, and the strict parameter matching among multiple secondary windings of a multi-winding transformer is a serious issue resulting in design difficulty and poor modularity. Two novel equalizers, (a) the single-switch equalizer using multi-stacked buck-boost converters and (b) the double-switch equalizer using a resonant inverter and voltage multiplier are presented in this chapter in order to address the above issues. 
The single-switch equalizer using multi-stacked buck-boost converters can be derived by multi-stacking any of the traditional buck-boost converters: SEPIC, Zeta, or Ćuk converters. In addition to the single-switch configuration, a multi-winding transformer is not necessary, and therefore, the circuit complexity can be significantly reduced as well as improving the modularity when compared with conventional equalizers, which require multiple switches and/or a multi-winding transformer. The detailed operation analysis was mathematically made for the isolated Ćuk converter-based topology.

The double-switch equalizer using a resonant inverter and voltage multiplier can be synthesized by, namely, combining a resonant inverter and a voltage multiplier. Although two switches are necessary, the required number of switches is sufficiently small to achieve a reduced circuit complexity. Since the number of required magnetic components is only one (i.e., a transformer), the size and cost of the equalizer are considered to be minimal when compared with equalizers requiring multiple magnetic components. The seriesresonant inverter was used as a resonant inverter, and a detailed operation analysis was separately made for the voltage multiplier and the series-resonant inverter.

The prototypes of the single- and double-switch equalizers were built for series-connected cells, and experimental equalization tests were performed for series-connected SCs and lithium-ion cells from initially-voltage-imbalanced conditions. The energies of cells with a high initial voltage are redistributed to the cells with a low initial voltage, and eventually, voltage imbalance of SCs and lithium-ion cells were almost perfectly eliminated by the equalizers after sufficient time elapsed.

\section{Author details}

Masatoshi Uno

Japan Aerospace Exploration Agency, Japan

\section{References}

Cao, J., Schofield, N. \& Emadi, A. (2008). Battery Balancing Methods: A Comprehensive Review, Proceedings of IEEE Vehicle Power and Propulsion Conference, ISBN 978-1-42441848-0, Harbin, China, September 3-5, 2008

Guo, K. Z., Bo, Z. C., Gui, L. R. \& Kang, C. S. (2006). Comparison and Evaluation of Charge Equalization Technique for Series Connected Batteries, Proceedings of IEEE Applied Power Electronics Conference and Exposition, ISBN 0-7803-9716-9, Jeju, South Korea, June 18-22, 2006

Isaacson, M. J., Hollandsworth, R. P., Giampaoli, P. J., Linkowaky, F. A., Salim, A. \& Teofilo, V. L. (2000). Advanced Lithium Ion Battery Charger, Proceedings of Battery Conference on Applications and Advances, ISBN 0-7803-5924-0, Long Beach, California, USA, January 1114,2000

Kim, C. H., Kim. M. Y., Kim. Y. D. \& Moon, G. W. (2011). A Modularized Charge Equalizer Using Battery Monitoring IC for Series Connected Li-Ion Battery String in an Electric 
Vehicle, Proceedings of IEEE International Power Electronics Conference, ISBN 978-1-61284956-0, Jeju, South Korea, May 30-June 3, 2011

Kutkut, N. H., Divan, D. M. \& Novotny, D. W. (1995). Charge Equalization for Series Connected Battery Strings. IEEE Transaction on Industry Applications, Vol. 31, No. 3, (May \& June 1995), pp. 562-568, ISSN 0093-9994

Lee, Y. S. \& Cheng, M. W. (2005). Intelligent Control Battery Equalization for Series Connected Lithium-Ion Battery Strings. IEEE Transaction on Industrial Electronics, Vol. 52, No. 5, (October 2005), pp. 1297-1307, ISSN 0278-0046

Nishijima, K., Sakamoto, H. \& Harada, K. (2000). A PWM Controlled Simple and High Performance Battery Balancing System, Proceedings of IEEE Power Electronics Specialist Conference, ISBN 0-7803-5692-6, Galway, Ireland, June 18-23, 2009

Pascual, C. \& Krein, P. T. (1997). Switched Capacitor System for Automatic Series Battery Equalization, Proceedings of IEEE Applied Power Electronics Conference and Exposition, ISBN 0-7803-3704-2, Atlanta, Georgia, USA, February 23-27, 1997

Uno, M. (2009). Interactive Charging Performance of a Series Connected Battery with Shunting Equalizer, Proceedings of IEEE International Telecommunications Energy Conference, ISBN 978-1-4244-2491-7, Incheon, South Korea, October 18-22, 2009

Uno, M. \& Tanaka, K. (2011). Single-Switch Cell Voltage Equalizer Using Multi-Stacked Buck-Boost Converters Operating in Discontinuous Conduction Mode for SeriesConnected Energy Storage Cells. IEEE Transaction on Vehicular Technology, Vol. 60, No. 8, (October 2011), pp. 3635-3645, ISSN 0018-9545

Uno, M. \& Tanaka, K. (2011). Influence of High-Frequency Charge-Discharge Cycling Induced by Cell Voltage Equalizers on Life Performance of Lithium-Ion Cells. IEEE Transaction on Vehicular Technology, Vol. 60, No. 4, (May 2011), pp. 1505-1515, ISSN 00189545

Uno, M. (2011). Supercapacitor-Based Electrical Energy Storage System, In: Energy Storage in the Emerging Era of Smart Grids, Carbone, R., pp. 21-40, InTech, ISBN 978-953-307-269-2, Rijeka, Croatia

Uno, M. \& Tanaka, K. (2011). Accelerated Ageing Testing and Cycle Life Prediction of Supercapacitors for Alternative Battery Applications, Proceedings of IEEE International Telecommunications Energy Conference, ISBN 978-1-4577-1248-7, Amsterdam, Netherland, October 9-13, 2011 